\title{
Acute abdomen caused by perforation of jejunal diverticulum
}

\author{
S N Deshmukh, S G Agarwal, R B Soni \\ Department of Surgery, Dr Vaishampayan Memorial Government Medical \\ College, Solapur, Maharashtra, India
}

Key words: Jejunal diverticulum; perforation; acute abdomen.

\section{Introduction}

Jejunal diverticula are rare with an incidence of less than $0.5 \%$. Pathologically they are pseudodiverticula of the pulsion type that only contain mucosa and submucosa [1]. They are believed to develop as the result of abnormalities in peristalsis, intestinal dyskinesia, and high segmental intraluminal pressures. The use of corticosteroids and non-steroidal anti-inflammatory drugs might play a causative role. [2] Jejunal diverticula are usually asymptomatic but can lead to acute complications like diverticulitis, bleeding, intestinal obstruction and perforation. [1] Because of its rarity here we report a case of acute abdomen caused by perforation of a jejunal diverticulum.

\section{Case history:}

A 62-year-old male presented to the emergency department with a 24-hour history of generalised abdominal pain and vomiting. The pain was sudden in onset, continuous and increased with movement and coughing. On physical examination he was febrile, dehydrated and had a tachycardia. Abdominal examination revealed generalized tenderness, guarding and rigidity. Bowel sounds were absent. An erect plain abdominal radiograph showed air under the right hemi-diaphragm suggesting perforation of a hollow viscus (Fig1).

Considering the possibility of a duodenal ulcer

Correspondence : Deshmukh SN

Jai Shri-Sadguru Nivas,

Plot No A/3 South part, Sonia Nagar,

Vidi Gharkul, Solapur - 413005.

Mobile no.: 09850680248

Tel.: 011-91-217-274-9461

Email : santoshkumarndeshmukh@gmail.com perforation an emergency exploratory laparotomy was performed .On exploration, two jejunal diverticula about $5 \mathrm{~cm}$ in diameter along the mesenteric border and about $15 \mathrm{~cm}$ and $25 \mathrm{~cm}$ away from duodenojejunal flexure were discovered. A perforation about 4 $\mathrm{mm}$ in diameter was found in the proximal diverticulum while the distal one was intact. (Fig 2) The rest of the small and large bowel was normal. Segmental resection of jejunum (containing both diverticula) with end to end jejuno-jejunostomy was performed. Postoperatively the patient made an excellent recovery. Histopathological examination of the resected specimen confirmed the diagnosis.

\section{Discussion:}

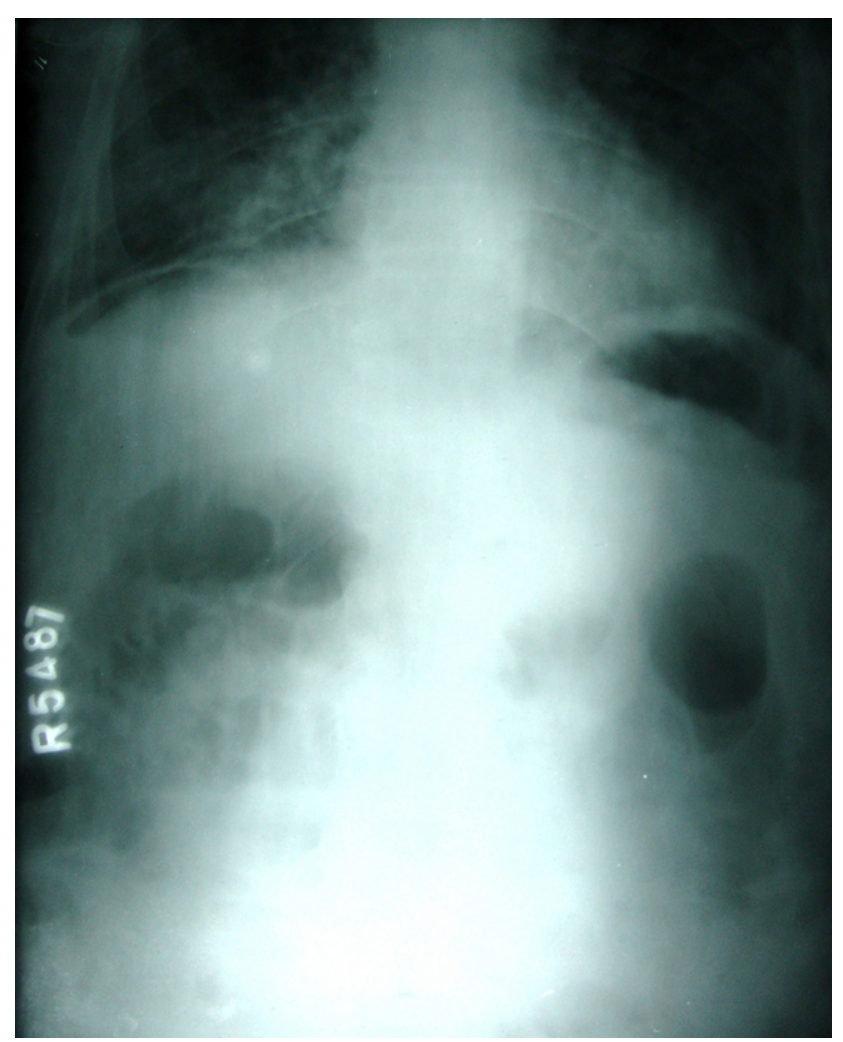

Figure 1: Plain abdominal radiograph 


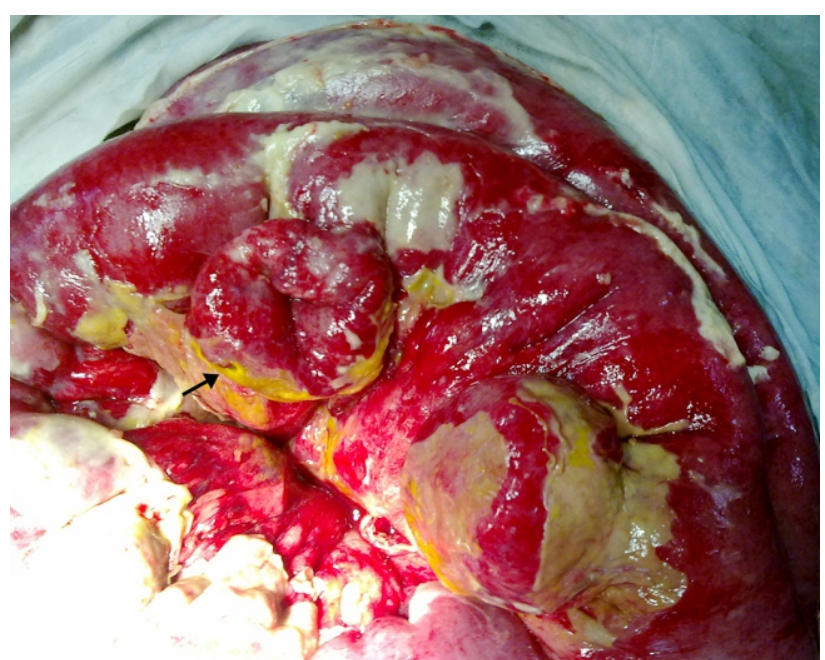

Fig 2: Intraoperative image of jejunal loop with diverticuli

Jejunal diverticulosis was first described by Somerling in 1794 and by Sir Astley Cooper in 1807. [3] Jejunal diverticula share similarities with colonic diverticula in that the mucosal herniations occur through gaps in the muscle layers along pathways of the visceral vessels. The size of these diverticula vary between a few milimeters to greater than ten centimetres. They occur twice as frequently in men as in women, normally after the age of 40 years. [4] Complications of jejunal diverticula are reported in 10 to $30 \%$ of patients. [1] Perforation is a rare complication.[3] The precipitating factors causing perforation have been reported as a necrotizing inflammatory reaction, blunt trauma to the abdominal wall and foreign body impaction in a diverticulum.[5] Perforation may present as a localized disease with or without generalized peritonitis. Preoperative diagnosis is difficult because clinical signs mimic acute appendicitis, acute cholecystitis, peptic ulcer perforation and colonic diverticulitis. [2] Since the diverticulum occurs at the mesenteric border, the perforation remains concealed within the mesentery resulting in localized peritonitis. This makes the diagnosis of perforated jejunal diverticula difficult.[5] Plain x-rays and CT scans are not sufficient for diagnosis. [5] The current treatment of choice for perforated jejunal diverticula causing generalised peritonitis is prompt laparotomy with segmental resection and primary anastomosis. [1] The reported mortality for perforation of jejunal diverticula is 21 40\%. [4]

\section{References}

1. Butler JS, Collins CG, McEntee GP. Perforated jejunal diverticula: a case report. J Med Case Rep 2010; 4:172

2. Ozdemir A, Ulas M, Karaman K, Teke Z, et al. Acute abdomen caused by a jejunal diverticulum perforation: A rare clinical entity. Anatol J Clin Investig 2010;4(3): 168-170.

3. Patel VA, Jefferis H, Spiegelberg B, Iqbal Q et al. Jejunal diverticulosis is not always a silent spectator: A report of 4 cases and review of the literature. World J Gastroenterol 2008; 14(38): 5916-5919

4. Peters R, Grust A, Gerharz CD, Dumon C, et al. Perforated jejunal diverticulitis as a rare cause of acute abdomen. Eur Radiol 1999; 9(7):1426-8.

5. Fass G, Colonval P. Perforation and abscess formation of a solitary jejunal diverticulum. Acta Chir Belg 2007; 107(2):222-224. 